\title{
Estratégias de ensino-aprendizagem de escala cartográfica linear junto aos estudantes de Geografia da UFAL ${ }^{1}$
}

\section{Teaching and learning strategies of cartographic linear scale among Geography Students at UFAL}

Umbelino Oliveira de Andrade

Doutor em Geografia, USP

Docente do Instituto de Geografia, Desenvolvimento e Meio Ambiente da Universidade Federal de Alagoas, Brasil umbelino@igdema.ufal.br

Mario De Biasi Doutor em Geografia, USP

Docente do Programa de Pós-Graduação em Geografia Humana Faculdade de Filosofia, Letras e Ciências Humanas da Universidade de São Paulo, Brasil

mdebiasi@usp.br

\begin{abstract}
Resumo
Parte significativa dos alunos de Geografia do IGDEMA/UFAL apresenta dificuldades na aprendizagem de escala cartográfica. Então lançou-se mão do desenvolvimento e implementação de alternativas de ensino-aprendizagem para essa superação junto a alunos do segundo período de 2013. Voltando-se ao socioconstrutivismo, aplicou-se o método de aula expositiva, considerando que o aprendizado ocorre com reconstrução interna de "instrumentos" e "signos" intermediado pelo professor. E também com base na andragogia, que considera o professor como facilitador da "aprendizagem útil" em prol da autonomia e da interação dos aprendizes com o seu ambiente de aprendizado, duas ações foram articuladas: a conscientização consistiu em expor que escala cartográfica tem importância específica, não sendo mera aritmética e sem clareza para a formação profissional; e a motivação envolveu a exposição da importância desse conteúdo respaldada em fundamentos legal, técnico e geográfico para sensibilizá-los também a se apossar afirmativamente de tal competência. Este processo envolveu as fases de avaliação prévia (exposição e prática de revisão) e avaliação definitiva (diálogos, exposições e práticas mais concentrados). No teste estatístico, após isso, para 1 grau de liberdade no nível de confiança de 95\%, o valor do qui-quadrado a ser excedido é 3,84 . Como se obteve 0,08 , não há evidência de evolução das notas dos alunos, comparando as avaliações.
\end{abstract}

Palavras-chave: Aprendizagem de escala cartográfica linear. Redefinição de prática pedagógica. Articulação da conscientização e motivação discentes. Recursos didático-pedagógicos incrementados.

\footnotetext{
Abstract

A meaningful part of Geography students from IGDEMA/UFAL have difficulties in learning cartographic scale. In face of that, the author made use of the development and implementation of teaching and learning alternatives in order to help the students to overcome those difficulties in the

${ }^{1}$ Trabalho baseado em tese de doutorado - "Escala cartográfica linear": estratégias de ensino-aprendizagem junto aos estudantes de Geografia do IGDEMA/UFAL - 2013 - defendida na Faculdade de Filosofia, Letras e Ciências Humanas, Universidade de São Paulo, em março de 2015. Apoio financeiro da Pró-Reitoria de Pesquisa e Pós-Graduação / Universidade Federal de Alagoas.
} 
year of 2013. Based on the socioconstructivism, the author used the expositive class method, considering that learning occurs with the internal reconstruction of "instruments" and "signs" intermediated by the teacher. The author also based his action on andragogy, which considers the teacher as a facilitator of the "useful learning" in favour of learners' autonomy and interaction with their learning environment. In this sense, two actions were articulated: awareness, which consisted in exposing that each cartographic scale has its specific importance; it is neither merely arithmetic, nor without clarity for professional formation; and motivation involved the exposition of the importance of this content supported in legal, technical and geographical basis so as to sensibilize them positively to be aware of such a competence. This process involved the phasis of previous evaluation (exposition and practice of revision) and definitive evaluation (dialogues, and more concentrated expositions and practices). In the statistical test, for a freedom degree in the confidence level of $95 \%$, the value of chi-square to be exceeded is 3,84 . Since 0,08 was obtained, there is no evidence of the evolution of students' degrees, in comparing the evaluations.

Keywords: learning of linear cartographic scale. Redefinition of pedagogical practice. Articulation of students' awareness and motivation. Incremented didactical-pedagogical resources.

\section{INTRODUÇÃO}

Alunos da graduação em Geografia do atual IGDEMA/UFAL, em parcela significativa, apresentam dificuldade na aprendizagem de escala cartográfica linear. Adotando uma ação docente redefinida, vislumbrando alunos adultos conscientes e críticos diante de resultados de tais aplicações e dos elementos instrumentais do processo educacional, acredita-se que eles se tornam agentes ativos do seu próprio processo de aprendizado. Poucos trabalhos pioneiros existentes constataram situações problemáticas em relação ao trabalho com escala cartográfica em suas abordagens: 1) Le Sann (1993, p. 51-52) aprofundou a questão da falta de noção básica dos estudantes para a aprendizagem de escala cartográfica, analisando uma turma de pós-graduandos - pois essa enfrentava problemas ao explicar essa noção a seus alunos -, e alunos do antigo primeiro grau. Então, tentou entender o encadeamento dos conceitos básicos na construção dessa noção. As crianças com mais dificuldades seriam as das camadas menos favorecidas da sociedade, pois enfrentariam problema de adequação de linguagem. No caso dos alunos universitários, concluiu que o problema seria similar, pois seus professores também usariam uma determinada linguagem que eles não dominam; 2) Bovo; Passini (2001, p. 323) constataram que enorme parte dos professores de Geografia não possui domínios quanto à utilização de escalas; 3) E conforme Sampaio (2006, p. 175 e 215), escala cartográfica é um assunto de certa dificuldade para o alunado, o que é confirmado por muitos dos entrevistados. Portanto, esses trabalhos trazem à tona as dificuldades com essa noção no âmbito da Geografia, ficando patentes os fatores raciocínio aritmético e linguagens avançadas.

As bases teóricas adotadas na presente pesquisa foram um conceito da psicologia pedagógica (VIGOTSKI, 2010), dois conceitos da teoria socioconstrutivista (VIGOTSKI, 2007) e andragogia (KNOWLES, 1980). O primeiro - processo educativo trilateral - compreende como três os 
participantes ativos: o aluno, o professor e as coisas inanimadas e o meio criado entre eles. O conceito da teoria socioconstrutivista internalização das funções psicológicas superiores se dá pela reconstrução interna de "instrumentos" e "signos" por parte do aluno ou aprendiz e seu consequente "desenvolvimento cognitivo", contando com auxílio de um professor, que "intermedia" o conhecimento entre o aprendiz e o ambiente do saber. E o conceito zona de desenvolvimento proximal se refere a relações entre o processo de desenvolvimento cognitivo e o "potencial de aprendizado". A teoria da andragogia, por fim, enfatiza a educação de adultos como um processo para a aprendizagem autodidática, autônoma, orientada, e uma redefinição do papel do professor como um facilitador disso. Apesar das correntes filosóficas que separam essas teorias - pragmática versus dialética -, o socioconstrutivismo também visa à autonomia cognitiva do aluno e a andragogia também demanda interação social. Assim, os objetivos foram: a) redefinir a prática pedagógica para haver contrapartida conscientizada dos alunos participantes no processo de aprendizagem; b) incrementar procedimentos didático-pedagógicos para auxiliar tais discentes no aprendizado mais autônomo do assunto focado; e c) abordar, de maneira sistemática e criteriosa, cálculos de elementos e modificações de escala cartográfica, para despertar a criticidade deles em relação a essa abrangência instrumental.

\section{ENSAIO EDUCACIONAL E APOIOS ESTATÍSTICOS}

Para a análise do ensaio empreendido de ensino e aprendizagem, necessitou-se de apoios estatísticos do requisito da fidedignidade e dos testes de diferenças.

\subsection{Ensaio de ensino-aprendizagem de escala cartográfica linear por meio de conscientização discente}

Os instrumentos de coletas de dados foram as avaliações prévia e definitiva. E a amostra trabalhada ficou assim caracterizada:

- Estudantes de graduação (bacharelado e licenciatura) em Geografia do IGDEMA/UFAL no período 2013-2 e que ingressaram majoritariamente em 2013-1;

- Quantitativo correspondente e coincidente de 12 alunos regulares das duas modalidades e dos dois turnos, totalizando 24 ;

- Controle através do conjunto unificado dos grupos de experimento para ser analisado em duas ocasiões;

- Universo composto por 564 estudantes do curso em foco, ingressantes majoritariamente nos períodos semestrais 2010-1 a 2013-2. 
Assim contextualizada a experiência em foco, às vésperas da avaliação prévia - durante 3 horas/aula por meio do método de aula expositiva -, foram ministradas noções básicas de escala cartográfica linear em uma sessão por meio de simples repasse de conteúdo com a finalidade de revisão do presumido conhecimento adquirido no ensino escolar, com a devida conferência dos exercícios solucionados, contando com recursos de materiais didáticos, principalmente a apostila "Revisão de escala cartográfica linear".

Buscando proximidade com a ideia andragógica, no experimento, após a avaliação prévia, um dos caminhos consistiu inicialmente em três recomendações prévias aos alunos. Na primeira apresentou-se um diagnóstico dos elementos que ofereceram maiores dificuldades para tais discentes para, daí, se buscar providências de superações, discutindo e dividindo isso com eles. Recomendouse que se empenhassem logicamente mais no estudo dos quesitos que lhes foram mais difíceis para obterem melhores resultados nos quesitos similares na avaliação definitiva. A segunda, por não compor o plano de ensino em virtude do tempo exclusivo para a abordagem do conteúdo, foi para a leitura imediata e atenta, na apostila "Conceitos elucidativos para escala cartográfica linear", dos conceitos resumidos de "Proporção" (regra de três), "Fração" (tamanho e modificação), "Dimensões gráfica e real" e "Detalhamento e generalização", e até mesmo fazer tais consultas em outras fontes, pois tudo isto lhes reforçaria para compreensão de linguagens a serem usadas, além de amenização da formação escolar inadequada. Assim também pode ser uma maneira de internalização de "instrumentos" e "signos". E a terceira recomendação foi para livres adaptações e resoluções ao final de cada grupo de exercícios similares para reforço de entendimento, adotando esses como modelo.

A partir daí, no processo de ensino-aprendizagem de escala cartográfica linear, buscou-se articular a conscientização e motivação dos alunos sobre a importância dos domínios teóricos e, particularmente, práticos desse assunto no processo de produção e aplicação do conhecimento geográfico, contando com empenho docente na facilitação e orientação em relação a essa aprendizagem e auxiliado por recursos didático-pedagógicos incrementados.

Lançou-se mão de recursos de exposição didática (projetor multimídia, quadro de giz, apostilas e mapas), recursos de materiais didáticos (mapas, apostilas, calculadora e régua) e estratégias didáticas (demonstrações, gravuras e exercícios de fixação). Também foram utilizados exercícios respondidos e suas conferências como forma de otimizar a velocidade do processo implementado diante do tempo programado, e - com a devida discussão em sala de aula envolvendo cálculos, comparações, simplificações e constatações -, foram abordados variados cálculos de elementos e modificações de escala cartográfica em diferentes escalas cartográficas, chamando a atenção em relação às menores escalas em função de distorção inevitável da projeção cartográfica usada. E organizou-se kit de estudo composto por apostilas, régua, tiras de papel, lápis, calculadora, além de pasta para tais armazenamentos. 
Uma importante estratégia de ensino-aprendizagem foi o uso da apostila "Escala cartográfica linear: importância e utilidade", contendo ilustrações (modelos, esquemas, quadros e mapas). Com a utilização de mapas e parcial de carta topográfica ${ }^{2}$ impressos em tamanho A4 foram realizados exercícios de fixação. Foram selecionados mapas familiares aos alunos, representando sua cidade, seu estado, sua região, etc. para constatações supostamente mais significativas. E, visando a "outras realidades", representações de outra região e de outro estado ${ }^{3}$ foram utilizadas.

Nessa apostila, em coerência com a apostila "Escala cartográfica linear: revisão" anteriormente citada -, dividiu-se o assunto em duas partes, embora mais detalhadas. A primeira Tamanhos de escala cartográfica e suas aplicações - sistematizou os seguintes pontos:

I) Escalas grandes, médias e pequenas. Para este tópico, os objetivos foram os de que os alunos: relatassem os efeitos dos tamanhos de escala, constatando que os denominadores grandes tornam a escala pequena e, vice-versa, os denominadores pequenos tornam a escala grande; agrupassem mentalmente escalas grande, média e pequena.

II) Comparações entre escalas. Aqui, objetivou-se que tais discentes constatassem que entre duas escalas numéricas a maior é a que tem o menor denominador e, vice-versa, a menor é a que tem o maior denominador.

Para esses dois pontos, como propositalmente não houve respostas prévias, foram incentivadas e orientadas discussões como forma de amadurecimento de ideias pertinentes, obtendose respostas satisfatórias.

III) Aplicação de escala numérica. Para isso foram necessárias conversões dos elementos gráficos e dos elementos reais. Então, objetivou-se que os discentes convertessem o numerador e o denominador da escala numérica para quaisquer unidades de medida derivadas do metro. Assim eles praticaram variados exercícios nesse sentido.

IV) Cálculos dos elementos de escala cartográfica. São tais: 1) Cálculo de distância real, no qual objetivou-se que os discentes calculassem a distância real de um fenômeno geográfico com base na sua correspondente medida no mapa e na escala do mapa. Os exercícios abordaram escalas numérica e gráfica. A resolução foi quase igual ao do Exercício similar da apostila anterior, mas com acréscimo

\footnotetext{
${ }^{2}$ Mapas e parcial de carta topográfica selecionados, pela ordem: Político do Brasil (IBGE, 201-?c); Região Nordeste (IBGE, 201-?e); Alagoas (IBGE, 201-?a); Parcial da carta Pilar/AL (IBGE, 1985b); Parcial da carta Maceió (IBGE, 1985a); Segunda parcial da carta Pilar/AL (IBGE, 1985b); Pontos extremos e fronteiras do Brasil (IBGE, 201-?d).

${ }^{3}$ Mapas, pela ordem: Região Sudeste (IBGE, 201-?f); Ceará (IBGE, 201-?b).
} 
do termo "Processo". Com auxílio deste simples detalhe complementar, argumentou-se junto aos discentes para a necessária conscientização da ideia por parte deles, enfatizando que tira de papel, ou outro recurso similar, nos auxilia na obtenção de dados para o "processamento" e obtenção de resultado. Portanto, tal ideia foi a criação de um elo de raciocínio entre etapas de tal cálculo, merecendo uma atenção crítica deles; 2) Cálculo de distância no mapa, cujo objetivo foi o de que os discentes, dispondo de distância real e de escala numérica, calculassem a distância gráfica possível para a representação cartográfica; 3) Cálculo de escala, cujo objetivo foi o de que eles simplificassem a relação de uma medida no mapa pela sua correspondente medida no terreno, concluindo que isso resulta numa fração representativa.

E a segunda parte - Ampliação e redução de escala cartográfica - teve como objetivos dos exercícios, contando com elementos de escala cartográfica previamente calculados, que os discentes calculassem a nova escala numérica em função de modificação da escala numérica original e/ou da distância gráfica; constatassem por cálculos que somente o elemento distância real logicamente não sofre alteração, ao contrário da distância gráfica e da própria escala cartográfica.

Para um dos seus exercícios lançou-se mão de mapas em três escalas muito diferentes entre si, ao mesmo tempo em que finalmente chamou-se atenção deles em relação ao nível de deformação provocada pela projeção cartográfica vinculada a escalas pequenas, embora não excessivo para o processo didático-educacional aplicado. Houve desdobramentos que demandaram comparações das distâncias gráficas entre os três mapas, verificação das proporcionalidades entre as escalas cartográficas desses mapas em função das comparações anteriores, além da verificação dos efeitos das escalas cartográficas desses mapas com relação à extensão de área e aos níveis de detalhe e de generalização.

A resolução foi quase igual ao do exercício similar da apostila "Escala cartográfica linear: revisão", e com acréscimo do termo "Processo". E argumentou-se também junto aos discentes que o cálculo desenvolvido equivale a uma lógica de "processamento", mas conforme observação de que há reciprocidade entre a alteração da distância gráfica e da escala cartográfica e, nessa lógica, se obter resultado correto.

E a apostila principal conteve, ao final de cada grupo de exercícios, recomendações para livres adaptações e resoluções de exercícios similares por parte deles, podendo os mesmos, no caso de cálculos envolvendo elementos de escala cartográfica, lançarem mão da lista inclusa de escalas numéricas e suas distâncias correspondentes entre gráficas e reais para efeito de reforço de entendimento.

Finalmente, no que tange às avaliações, tanto a prévia quanto a definitiva foram compostas por sete questões distribuídas equivalentemente da seguinte maneira: as cinco primeiras referiram-se 
aos elementos da escala cartográfica - três para cálculos de distância real (escalas numéricas e gráfica), uma para cálculo de distância gráfica, uma para cálculo de escala - e as duas últimas, às modificações de escala cartográfica.

\subsection{Requisitos básicos da avaliação de aprendizagem e testes de diferenças}

Os quesitos ou itens da avaliação definitiva, embora similares aos da prévia, foram mais complexas em coerência com o processo de ensino-aprendizagem subsequente, na expectativa de que os dados da avaliação de aprendizagem, para serem utilizados com rigor estatístico por meio dos testes de diferenças, devem advir previamente de instrumento de avaliação submetido ao processo da validação.

\subsubsection{Requisitos básicos para validação do teste de aprendizagem}

Visando tornar o teste de aprendizagem hábil como instrumento de avaliação, assegurando uma qualidade dos seus dados, requisitos mínimos foram obrigatórios, em conformidade com Bisquerra et al. (2004, p. 214), Moreira; Veit (2010, p. 173) e Viana (1982, p. 21): validade e fidedignidade. A validade verifica até que ponto a avaliação está medindo o que se supõe, conforme objetivos (AUSUBEL et al., 1980, p. 507; MOREIRA; VEIT, 2010, p. 174; SILVEIRA, 1993, p. 83). Assim, verificou-se o requisito mínimo de validade através da análise de conteúdo, em conformidade com Moreira; Veit (2010, p. 178) - que é o mais importante dos tipos de validade (VIANA, 1982, p. 21 e 172) -, que se refere a uma amostra adequada e representativa de um universo do conteúdo (itens), está sendo medido no examinando após a sua experiência educacional (AUSUBEL et al., 1980, p. 508; BISQUERRA et al., 2004, p. 216; MOREIRA; VEIT, 2010, p. 175; SILVEIRA, 1993, p. 73; VIANA, 1982, p. 21, 172-173). Nesse sentido, foi feita uma relação ponderada entre itens de escala cartográfica linear e respectivos objetivos, segundo importância do aprendizado.

Daí, escolheu-se como amostra "escala cartográfica linear e alterações de escala". Assim, considerando essa amostra e seu conhecimento discente expresso natural e estatisticamente em graus variados de aprendizagem, assegurou-se minimamente o requisito da validade de conteúdo do instrumento de medida de aprendizagem aplicado, cujos dados puderam ser utilizados no segundo requisito a seguir da avaliação definitiva.

$\mathrm{O}$ requisito da fidedignidade, por sua vez, refere-se à estabilidade, à reprodutibilidade, à precisão das medidas obtidas com isso (BISQUERRA et al., 2004, p. 216; MOREIRA; VEIT, 2010, p. 174). Seu método estatístico básico é o coeficiente de fidedignidade da correlação interna entre os quesitos com aplicação em um número apreciável de sujeitos (MOREIRA; VEIT, 2010, p. 174 e 176). 
Para seu grau necessário, se forem utilizados para propósitos de pesquisa, são toleráveis coeficientes em torno de 0,7 (AUSUBEL et al., 1980, p. 511; SILVEIRA, 1993, p. 83; VIANA, 1982, p. 167).

Assim, adotou-se como tipo de instrumento de medida o "teste de resposta aberta e simplificada" que, por apresentar carência de fidedignidade nos seus escores, exigiu um processo de planejamento e minimização de sua limitação. Em compensação, os quesitos de solução aberta de problemas são menos influenciados pela memória mecânica além de testar diretamente a capacidade de aplicar o conhecimento retido (AUSUBEL et al., 1980, p. 509; VIANA, 1982, p. 81)

Para o cálculo do coeficiente, cada quesito corrigido nesse processo gerou um escore e todos os escores somados geraram um escore total para cada examinando, resultando na medida do mesmo conhecimento adquirido para identificar quesitos discrepantes e tais exclusões por não se correlacionarem com os outros. A seguir, respeitou-se a proporção mínima de examinandos igual a 5 vezes o número de quesitos, conforme recomendação a que chama atenção Silveira (1993, p. 78), tendo em vista uma análise de consistência interna para melhoria do instrumento de avaliação que foi aplicado. Assim, como coeficiente de fidedignidade do escore total nesse instrumento, utilizou-se o alfa de Cronbach.

Considerando o intermediário grau de precisão dos escores disponibilizados pelo teste de aprendizagem aplicado, por ser de resposta aberta e simplificada, buscou-se mitigar essa limitação por meio de procedimentos administrativos para alcançar um incremento compensatório. Então, adaptando recomendações de Viana (1982), foram adotadas providências gerais em relação:

- ao próprio teste (número de quesitos não elevado para teste homogêneo; maior homogeneidade; nível médio de dificuldade; quesitos menos interdependentes; apresentações gráficas corretas; cinco respondentes por item);

- à explicitação dos objetivos cognitivos;

- ao ambiente educacional (instalações materiais gerais e não sujeitas à influência de fatores adversos);

- aos examinandos e sua contrapartida (contribuições para que tivessem motivação adequada; tempo suficiente na realização do teste);

- a instruções e recomendações (linguagem clara, direta e sucinta; recomendações para leitura inicial de todas as questões, revisão final das respostas etc.);

- a últimas providências e conferências.

Em virtude da disposição de apenas 24 respondentes, para subsídio na melhora do instrumento de medida de aprendizagem, inicialmente foi possível eliminar dois quesitos muito discrepantes - referentes à modificação de escala -, em virtude das suas correlações Q mais baixas 
com o escore total $\mathrm{T}^{4}$. Assim o cálculo do coeficiente de Cronbach resultou em 0,69. Embora esse coeficiente tolerável tenha sido alcançado, não se obteve a disposição de 5 respondentes por quesito, o que gerou a obrigação de se eliminar mais um. Daí, reexaminou-se a matriz dos resultados da avaliação definitiva e eliminou-se o quesito referente à dimensão gráfica, cujo recálculo do escore total de cada examinando resultou $\alpha=0,67$. Mesmo assim confirmou-se o requisito da fidedignidade dessa avaliação, contando com a média de 6 respondentes por quesito.

Portanto, a validação da avaliação aplicada se confirmou pelo cumprimento dos requisitos da validade e fidedignidade, o que tornou os seus dados finalmente habilitados para os procedimentos a seguir.

\section{$\underline{2.2 .2}$ Testes de diferenças}

Para os dados anteriores colhidos, as alternativas estatísticas foram os testes de significância não paramétricos, por utilizar níveis de mensuração nominal (teste qui-quadrado) e ordinal (teste da mediana), em conformidade com Levin; Fox (2004, p. 294), a seguir sintetizadas.

O teste qui-quadrado $\left(\chi^{2}\right)$ de Pearson indica a significância da diferença entre um conjunto de frequências observadas $\left(f_{o}\right)$ e um conjunto de frequências esperadas $\left(f_{e}\right)$. Quanto maiores essas diferenças, maior é a chance de uma diferença significativa, sugerindo que a hipótese nula não é plausível. Pela fórmula: $\chi^{2}=\sum \frac{\left(f_{0}-f_{e}\right)^{2}}{f_{e}}(\mathrm{LEVIN}$; FOX, 2004, p. 296), pode-se aplicar um quiquadrado de duas variáveis para testar uma tabulação cruzada, comparando-se também frequências observadas com frequências esperadas sob a hipótese nula (LEVIN; FOX, 2004, p. 300). Pela fórmula: $f_{e}=\frac{(\text { total marginal de linha })(\text { total marginal de coluna })}{N}$.

Então, em conformidade com Levin; Fox (2004, p. 315), as exigências para tal uso que tiveram que ser atendidas foram: comparação entre duas ou mais amostras independentes, dados nominais, amostragem aleatória e frequências esperadas nas celas não muito pequenas.

Em tabelas 2 × 2, a exigência é que todas as frequências esperadas sejam, no mínimo, iguais a 5. Além disso, podem ocorrer distorções se as frequências esperadas forem inferiores a 10. Daí, a fórmula corrigida do qui-quadrado para pequenas frequências esperadas é: $\chi_{\text {Yates }}^{2}=\sum \frac{\left(\left|f_{0}-f_{e}\right|-0,5\right)^{2}}{f_{e}}$ (LEVIN; FOX, 2004, p. 313-314). Essa correção é recomendada somente quando $\mathrm{gl}^{5}=1$

\footnotetext{
${ }^{4}$ Como não se obteve adesão mínima de 30 examinandos regulares, não se tornou apropriado o cálculo do coeficiente de correlação $r$ de Pearson para cada quesito, restando a alternativa de exame de lista ordenada dos dados e procura dos valores amostrais mínimo e máximo, determinando se eles estavam ou não muito afastados dos outros valores típicos em relação a cada quesito.

${ }^{5}$ Graus de liberdade - (linha da tabela - 1) x (coluna da tabela - 1) -, em comparações de pequenas amostras, são uma compensação estatística pelo fato de não se pode assumir que a distribuição amostral de diferenças toma a forma da curva normal (LEVIN; FOX, 2004, p. 482).
} 
(CALLEGARI-JACQUES, 2003, p. 140). E além do mais, também não deve ser aplicada para diferenças entre $f_{o}$ e $f_{e}$ menores que 0,5 (MOTTA, 2006, p. 162). Seus resultados são comparados com valores críticos da distribuição $\chi^{2}$ tabelados.

Para a situação em que se comparam vários grupos, não há regra fixa para as frequências mínimas das celas, embora deva haver cuidado para que a maioria dessas seja no mínimo 5 (LEVIN; FOX, 2004, p. 315-316). Ainda assim, uma abordagem mais moderna considera que em tabela de dupla entrada com duas linhas e mais de duas colunas o $\chi^{2}$ pode ser calculado se todos as $f_{e}$ forem $\geq$ 1 (CALLEGARI-JACQUES, 2003, p. 140-141).

Para verificar se a diferença amostral resulta de uma diferença populacional real e não apenas do erro amostral, usa-se um nível de significância $\alpha$ de 0,05 (ou nível de confiança de 95\%) (LEVIN; FOX, 2004, p. 230-231).

E para o teste aplicado, que utilizou também mensuração ordinal, a mediana (Mdn) foi mais apropriada em virtude da assimetria acentuada da distribuição dos dados, em conformidade com Levin; Fox (2004, p. 88, 91 e 97), envolvendo teste de significância qui-quadrado em uma tabulação cruzada - conforme acima sintetizado -, verificando-se se os escores estavam situados acima ou abaixo da mediana de dois grupos combinados. Também, para essa mensuração, usou-se a correção de Yates para problema 2 × 2 com pequenas frequências esperadas, segundo recomendação de Levin; Fox (2004, p. 316).

Então, as condições para esse uso, ainda em conformidade com Levin; Fox (2004, p. 318), foram: comparação entre duas ou mais medianas provenientes de amostras independentes, dados ordinais ou dados intervalares e amostragem aleatória da já caracterizada totalidade dos estudantes do curso em foco. E os resultados também foram confrontados com tabela de valores críticos da distribuição qui-quadrado $\chi^{2}$.

E por fim, ao perpassar tais etapas obrigatórias, tanto da validação do instrumento de avaliação aplicada, quanto dos testes de diferenças, a investigação principal focou o Teste 1 - “A evolução das notas reformuladas de cada aluno como reflexo da aplicação do processo de ensinoaprendizagem de escala cartográfica linear, comparando a avaliação prévia e a avaliação definitiva".

Também se investigou, complementarmente, a proporção exclusiva das notas iguais ou superiores a $7^{6}$ da avaliação definitiva. Assim, tratou-se de indícios da evolução das notas apenas nessa avaliação e em função dos turnos e das modalidades distintos das turmas. Então, como não foi recomendável a aplicação do teste da mediana para uma complementação por meio das variáveis "Notas obtidas reformuladas" e "Modalidades de cursos" (Licenciatura e Bacharelado), em virtude de frequências esperadas abaixo de 5, adaptaram-se essas, bem como as variáveis pertinentes "Notas

\footnotetext{
${ }^{6} \mathrm{Na}$ UFAL a média mínima de 7 é condição para aprovação direta do discente, ou seja, que não necessita de submissão à recuperação e/ou à avaliação final.
} 
obtidas reformuladas" e "Turnos de aula" (tarde e noite), que, por sua vez, credenciou-se para esse teste, tornando-se mais abrangente $(2 \times 4)^{7}$, contudo, também complementar. Assim, o Teste 2 ficou intitulado "A proporção das notas iguais ou superiores a 7, reformuladas da avaliação definitiva em relação a cada um dos quatro grupos de alunos em função das modalidades e dos turnos".

\section{RESULTADOS}

Como um balanço interessante e inicial em função das obrigatoriedades acima, destacaramse dados das notas por meio das medidas de tendência central, respectivamente modas, medianas e médias.

Com base nas tabelas das notas originais obtidas sequencialmente pelos 24 alunos:

- a avaliação prévia: $\mathrm{Mo}=6,4 ; \operatorname{Mdn}=5,5 ;$ e $\bar{M}=5,5$.

- a avaliação definitiva: $\mathrm{Mo}=7,9$ e 5,0; $\mathrm{Mdn}=5,2 ;$ e $\overline{\mathrm{M}}=5,3$.

Com base nas tabelas das notas reformuladas obtidas sequencialmente pelos 24 alunos:

- $\quad$ avaliação prévia: $\mathrm{Mo}=10$ e 8,$1 ; \mathrm{Mdn}=7,5 ;$ e $\overline{\mathrm{M}}=6,6$.

- $\quad$ avaliação definitiva: $\mathrm{Mo}=10 ; \mathrm{Mdn}=7,5 ;$ e $\overline{\mathrm{M}}=6,6$.

Com isso, as medidas da mediana e da média, seja pelas notas originais, seja pelas notas reformuladas, evidenciaram que a estabilidade praticamente se manteve entre as notas das duas avaliações, embora as da moda apontaram alguma evolução.

Em relação ao resultado da investigação principal, no Teste 1, para 1 grau de liberdade no nível de significância de 0,05 (ou nível de confiança de 95\%), o valor tabelado do qui-quadrado a ser excedido é 3,84. Como se obteve qui-quadrado de 0,08 , não se pôde rejeitar a hipótese nula. Portanto, não há evidência para se concluir pela evolução das notas de cada aluno, ao se comparar as avaliações prévia e definitiva.

E em relação ao resultado da investigação complementar, no Teste 2, para 3 graus de liberdade no nível de significância de 0,05 (ou nível de confiança de 95\%), o valor do qui-quadrado a ser excedido é 7,81. Como se obteve qui-quadrado de 3,42, não se pôde rejeitar a hipótese nula. Portanto, não há evidência para se concluir que a proporção das notas iguais ou superiores a 7 , reformuladas da avaliação definitiva, é diferente entre as quatro turmas de graduação, unidas em duas no processo em foco, em função dos turnos e das modalidades.

\footnotetext{
${ }^{7}$ Com tabela nesse "formato", o grau de liberdade resultou em 3, conforme destacado mais adiante.
} 
Para uma conferência parcial, embora também com finalidade complementar, em relação a algumas variáveis do Teste 2 , aplicou-se, igualmente ao Teste 1 , um teste da mediana com as variáveis "nível das notas reformuladas da avaliação definitiva" e "turnos das aulas". Assim, para 1 grau de liberdade no nível de significância de 0,05 (ou nível de confiança de 95\%) o valor do qui-quadrado a ser excedido é 3,84. Mas, como resultou apenas em 0,18 aplicando a correção de Yates, não se rejeitou a hipótese nula. Portanto, não há evidência da diferença do nível das notas da avaliação definitiva dos alunos de graduação, ao se comparar os turnos da tarde e da noite. Tal conferência é coerente ao do Teste 2.

\section{DISCUSSÃO}

Em virtude de um cronograma reformulado para se ajustar à aproximação do fim do cronograma letivo semestral da UFAL, teve-se que cancelar duas programações: a elaboração de um roteiro discente, que seria um importante recurso didático e teste piloto das avaliações. O roteiro, que complementaria as três recomendações prévias mencionadas, teria a função de material paradidático, aglutinando ilustrações elucidativas, estratégias auxiliares de raciocínio e orientações de estudos dirigidos propriamente dito, reforçando o objetivo de incremento didático-pedagógico para contribuir, de maneira mais eficaz possível, com a auto didática dos participantes, encorajando-os à autonomia nesse sentido. E a aplicação do teste piloto redirecionaria os critérios de abordagens dos conteúdos que acusaram discrepâncias estatísticas, especialmente a parte de modificações de escala cartográfica, otimizando esforços de ensino-aprendizagem que foram empreendidos.

Situações adversas certamente contribuíram com limitações à aprendizagem pretendida para o conjunto dos alunos participantes, tais como: uma parcela da turma vespertina parecia não ter vontade de aprender, ocasionalmente houve um déficit de alunos em virtude da realização do Exame Nacional do Ensino Médio como oportunidade de mudança de curso, cansaço físico de alguns nas aulas da noite, sala de aula eventualmente com pouca ventilação, uma queda de energia elétrica, os quatro monitores praticamente não foram procurados, etc. Ora, Cavalcanti (1999) e Nogueira, M. (2009) chamam a atenção de fatores limitantes como: dificuldades de raciocínio lógico matemático, dificuldade de conciliar vida acadêmica, profissional e pessoal, etc. Enfím, em graus e combinações diferentes, tais fatores interferem em qualquer processo educativo.

E as constatações obtidas se assemelham aos trabalhos da problemática em foco no âmbito geográfico, no que tange ao raciocínio aritmético e de linguagem - Sampaio (2006), Bovo; Passini (2001) e Le Sann (1993). Na busca de uma maneira de reverter tal problemática, foram tentadas na presente pesquisa soluções didático-pedagógicas incrementadas, cujo resultado desejável ainda demanda mais reflexões, esforços e tempo hábil. 
Aparentando simplicidade, é surpreendente o desdobramento do assunto de escala cartográfica linear, o que demanda aumento de carga horária na sua ministração. E o desdobramento é tal que esse conteúdo estaria apto a ser ao menos um tópico especial a ser ministrado, pois se justifica pelas relativas contribuições aos estudos geográficos e oportunidade de raciocínios auxiliados por manipulações aritméticas, haja vista os desafios que oferece aos estudantes de uma ciência humana.

\section{CONCLUSÕES}

Três situações impediram a superação do problema de aprendizagem de escala cartográfica linear pelos alunos, em virtude de fatores limitantes, conforme destacados. Em relação à primeira, o processo aplicado acabou tornando-se ambicioso para o tempo programado vinculado à condição dos alunos com dificuldades persistentes.

Na outra situação, observa-se ainda como um desafio todos os discentes praticarem durante as aulas, e/ou em outro horário, exercícios variados por meio de cálculos, mesmo com auxílio de exercícios solucionados como forma de otimizar o tempo limitado, visando paulatinamente a tal consolidação.

E por último, a parte de modificações de escala cartográfica se revelou um empecilho à aprendizagem integral do assunto em foco para a grande maioria dos discentes, mesmo que conciliando-se com Silveira (1993) -, a sua junção com elementos de escala cartográfica fosse pertinente com o assunto geral e não tão desarmônico com o pressuposto da homogeneidade indicativa do mesmo conhecimento.

Logo, o processo empreendido precisa ser revisto em parte, pois também, é necessário ressaltar, não houve retrocesso das notas dos discentes participantes.

\section{REFERÊNCIAS}

AUSUBEL, D. P.; NOVAK, J. D.; HANESIAN, H. Psicologia educacional. 1. ed. Tradução de Eva Nick. Rio de Janeiro: Interamericana, 1980. 625p.

BISQUERRA, R.; SARRIERA, J. C.; MARTÍNEZ, F. Introdução à estatística: enfoque informático com o pacote estatístico SPSS. 1. ed. Tradução de Fátima Murad. Porto Alegre: Artmed, 2004. 255p.

BOVO, M. C.; PASSINI, E. Y. A Cartografia do professor. Boletim de Geografia, Maringá, v. 19, n. 2, p. 320-325, 2001.

CALLEGARI-JACQUES, S. M. Bioestatística: princípios e aplicações. 1. ed. Porto Alegre: Artmed, 2003. 255p.

CAVALCANTI, R. A. Andragogia: a aprendizagem nos adultos. Revista de Clínica Cirúrgica da Paraíba, João Pessoa, v. 4, n. 6, p. 44-51, 1999. 
INSTITUTO BRASILEIRO DE GEOGRAFIA E ESTATÍSTICA. Alagoas. Rio de Janeiro, [201?a]. 1 mapa. Escala 1:1.500.000. Disponível em: $<\mathrm{ftp}$ //geoftp.ibge.gov.br/mapas_tematicos/mapas_escolares/ensino_medio/mapas_estaduais/pdf/ala goas $>$. Acesso em: 23 ago. $201 \overline{3}$.

INSTITUTO BRASILEIRO DE GEOGRAFIA E ESTATÍSTICA. Ceará. Rio de Janeiro, [201-?b]. 1 mapa. Escala 1:2.500.000. Disponível em: $<\mathrm{ftp}$ //geoftp.ibge.gov.br/mapas_tematicos/mapas_escolares/ensino_medio/mapas_estaduais/pdf/cea ra>. Acesso em: 23 ago. 2013.

INSTITUTO BRASILEIRO DE GEOGRAFIA E ESTATÍSTICA. Político. Rio de Janeiro, [201-?c]. 1 mapa. Escala 1:24.000.000. Disponível em: $<$ http://atlasescolar.ibge.gov.br/mapas-atlas/mapas-dobrasil/federacao-e-territorio>. Acesso em: 12 ago. 2013.

INSTITUTO BRASILEIRO DE GEOGRAFIA E ESTATÍSTICA. Pontos extremos e fronteiras. Rio de Janeiro, [201-?d]. 1 mapa. Escala 1:25.000.000. Disponível em: $<$ http://atlasescolar.ibge.gov.br/mapas-atlas/mapas-do-brasil/federacao-e-territorio>. Acesso em: 23 ago. 2013.

INSTITUTO BRASILEIRO DE GEOGRAFIA E ESTATÍSTICA. Região Nordeste. Rio de Janeiro, [201-?e]. 1 mapa. Escala 1:9.000.000. Disponível em: <ftp://geoftp.ibge.gov.br/mapas_tematicos/mapas_escolares/ensino_medio/regiao_nordeste.pdf $>$. Acesso em: 23 ago. 2013.

INSTITUTO BRASILEIRO DE GEOGRAFIA E ESTATÍSTICA. Região Sudeste. Rio de Janeiro, [201-?f]. 1 mapa. Escala 1:6.000.000. Disponível em: <ftp://geoftp.ibge.gov.br/mapas_tematicos/mapas_escolares/ensino_medio/regiao_sudeste.pdf $>$. Acesso em: 23 ago. 2013.

INSTITUTO BRASILEIRO DE GEOGRAFIA E ESTATÍSTICA. Maceió. Rio de Janeiro, 1985a. 1 mapa. Escala 1:50.000. Disponível em: <http://biblioteca.ibge.gov.br/d_detalhes.php?id=64224>. Acesso em: 12 ago. 2013.

INSTITUTO BRASILEIRO DE GEOGRAFIA E ESTATÍSTICA. Pilar. Rio de Janeiro, 1985b. 1 mapa. Escala 1:50.000. Disponível em: <http://biblioteca.ibge.gov.br/detalhes.php?id=62836>. Acesso em: 12 ago. 2013.

KNOWLES, M. S. The modern practice of adult aducation. New York: Cambridge, 1980. 400p.

LE SANN, J. G. Elaboração de material pedagógico para o aprendizado de noções geográficas de base, no Brasil. Caderno de Geografia, Belo Horizonte, v. 4, n. 5, p. 51-69, 1993.

LEVIN, J.; FOX, J. A. Estatística para ciências humanas. Tradução de Alfredo Alves de Farias. Revisão técnica de Ana Maria Lima de Farias. 9. ed. São Paulo: Prentice Hall, 2004. 497p.

MOREIRA, M. A.; VEIT, E. A. Fidedignidade e validade de testes e questionários. In: MOREIRA, M. A.; VEIT, E. A. Ensino superior: bases teóricas e metodológicas. São Paulo: E. P. U., 2010. parte II, p. 173-180.

MOTTA, V. T. Bioestatística. 2. ed. Caxias do Sul: Educs, 2006. 190p. 
NOGUEIRA, M. O. G. Aprendizagem do aluno adulto: implicações para a prática docente no ensino superior. Curitiba: Ibpex, 2009. 144p.

SAMPAIO, A. C. F. A cartografia no ensino de licenciatura em geografia: Análise da estrutura curricular vigente no país, propostas na formação, perspectivas e desafios para o futuro professor. 2006. 637 f. Tese (Doutorado em Geografia) - Instituto de Geociências, Universidade Federal do Rio de Janeiro, Rio de Janeiro, 2006.

SILVEIRA, F. L. Validação de testes de papel e lápis. In: MOREIRA, M. A.; SILVEIRA, F. L. Instrumentos de pesquisa em ensino e aprendizagem: a entrevista clínica e a validação de testes de papel e lápis. Porto Alegre: EDIPUCRS, 1993. segunda parte, p. 67-93.

VIANA, H. M. Testes em educação. 4. ed. São Paulo: IBRASA, 1982. 220p.

VIGOTSKI, L. S. A formação social da mente: o desenvolvimento dos processos psicológicos superiores. COLE, M. (Org.). Tradução de José Cipolla Neto. São Paulo: Martins Fontes, 2007. 182 p.

VIGOTSKI, L. S. Psicologia pedagógica. Tradução de Paulo Bezerra. 3. ed. São Paulo: WMF Martins Fontes, 2010. 561p. 